\title{
Which Raga is Restful and which Restless? A Statistical Comparison between Todi and Bhairavi
}

\author{
By Poonam Priyadarshini* \\ Soubhik Chakraborty
}

\begin{abstract}
Music is one of the oldest forms of art, which people listen to, to experience joy. A raga, in Indian classical music, is a melodic structure with fixed notes and a set of rules characterizing a certain mood conveyed through performance. In recent years we have seen a lot of research being done on music signals pertaining to several issues such as how or why music really evokes emotion in the human mind. It is not surprising that listeners have experienced different emotional feelings while listening to different ragas. In this paper we are doing a comparative statistical study between two ragas, one being aesthetically known to be restful and the other restless in nature. While the statistical analysis confirms the aesthetic point of view, it is also an eye opener to the fact that sad music, which is generally connected with higher note duration and hence thought to be restful, need not always be so!
\end{abstract}

\section{Introduction}

Indian classical music has two acknowledged forms -- North Indian or Hindustani classical music and South Indian or Carnatic classical music. In both forms, the raga is taken as the nucleus. A raga is defined as a melodic structure with fixed notes and a set of rules is maintained while playing the notes so that a certain emotion is evoked by the performance. By a set of rules we mean that note sequences are rendered in aroh (ascent) and in awaroh (descent) while singing the raga, the specific note combinations are typical in a raga and by the way a particular note or a particular note combination is rendered it is quite possible to determine which raga is rendered. In Indian classical music, it is observed that the performer has infinite freedom to express the musical emotion despite the aforesaid rules. The tonic Sa can be kept at any pitch (which is a major difference with western classical music where a particular musical piece is, in general, in a particular key from where we get harmony and counterpoint; Indian classical music does not support harmony and counterpoint and is monophonic i.e. having a single melody

\footnotetext{
* Assistant Professor, Department of Electronics and Communication Engineering, Birla Institute of Technology, Patna, India.

+ Professor, Department of Mathematics, Birla Institute of Technology, Mesra, Ranchi, India.
} 
line) and melody and rhythm are the technical ingredients. Indian classical music is very rich in emotion and devotion while western classical music seems to be richer in technicalities. While rendering a raga, a singer uses a set of five or more notes from the fixed scale of seven notes, to construct a melody. Sa, being the tonic, has to be present. Also between $\mathrm{Ma}$ and $\mathrm{Pa}$ one has to be present. A thaat is a raga group based on a scale. There are ten thaats named a Bilawal, Kalyan, Khamaj, Bhairav, Poorvi, Marwa, Kafi, Asavari, Bhairavi and Todi; if one were to pick a raga at random, it should be possible to find that it is based on one or another of these thaats. Two ragas using even the same notes can evoke quite different emotions sometimes even opposite emotions, like sadness and happiness. The probabilities of a note also depend on the raga concerned. Important notes in the raga will have higher probabilities. The most characteristic patterns of notes in a raga are described as "pakad," a catch phrase by which the raga can be easily recognized. A note with lower probability carries more surprise when it comes. It has been argued that the most important note is not necessarily the one which appears the maximum number of times in a raga. Rather the most important note statistically speaking is one which has a high probability and maintains this probability more than the rest from instance to instance of note occurrence. This gives rise to a concept of statistical stability which is different from the concept of (psychological) pitch stability, which is based on note duration.

\section{Related Work}

For a sound literature on statistics in musicology, see the article by Beran and Mazzola, ${ }^{1}$ the book by Beran, ${ }^{2}$ while readers interested in computational musicology in the context of Hindustani music are referred to the book by Chakraborty et al. $^{3}$ The article by Parncutt ${ }^{4}$ on how researchers can help artists is also of interest. Some of the references cited in the aforesaid references are also helpful especially the article by Castellano et al. ${ }^{5}$ Readers

1. Jan Beran and Guerino Mazzola, "Analyzing Musical Structure and Performance-A Statistical Approach," Statistical Science 14, no. 1 (1999).

2. Jan Beran Statistics in Musicology (New York: Chapman and Hall, 2004).

3. Soubhik Chakraborty, Guerino Mazzola, Swarima Tewari, Moujhuri Patra Computational Musicology in Hindustani Music (Springer International Publishing, 2014).

4. Richard Parncutt "Can researchers help artists? Music performance research for music students," Music Performance Research 1, no. 1 (2007).

5. Mary A. Castellano, Jamshed J. Bharucha, Carol L. Krumhansl "Tonal hierarchies in the music of north India," Journal of Experimental Psychology 113, no. 3 (1984). 
interested in musical signal processing may consult the book by Klapuri and Davy. ${ }^{6}$

\section{Methodology}

We have taken two different ragas by Bhairavi and Todi and calculated note duration as the difference between the departure time and onset time of the note in sec. For each sequence of notes, a frequency distribution is found from the intervals and inter onset interval (IOI) i.e. time difference between the onsets of two successive notes in sec. The statistical analysis of the data reveals some interesting features that differentiate the two ragas.

\section{Experimental Results and Discussion}

A music signal differs from a speech signal. Although both are continuous functions of time, a speech signal is a continuously varying functions of time while a music signal remains stable for the duration of a note and then it jumps to the (fundamental) frequency of the next note. Thus musical notes can be easily identified simply by looking for the stability of the corresponding fundamental frequencies (which determine the pitch). The fundamental frequencies were extracted using the Praat software and saved in a text file. Notes were detected by looking for stability in fundamental frequencies and accordingly the means and standard deviations of the note durations of the notes that were computed in sec. The inter onset interval time values were also obtained from the same file.

The experimental results of the mean note duration values of all notes in the ragas, Todi which is restful and Bhairavi which are musically acclaimed as restful and restless respectively, are summarized in Table 1 and the corresponding bar diagram is shown in Figure 1. It is not very difficult to see from the diagram which raga is restful and which restless! The mean duration of every note is higher in Todi compared to Bhairavi. Notice that the note duration of note 1 is the highest in both ragas. This is perhaps because note 1 is the tonic Sa, the note of origin or the base note.

6. Anssi Klapuri, and Manuel Davy (eds.) Signal Processing Methods for Music Transcription (New York: Springer, 2006). 
Table 1. Mean Note Duration of Ragas Todi and Bhairavi

\begin{tabular}{|c|c|c|}
\hline Notes & $\begin{array}{c}\text { Mean note duration in sec for } \\
\text { TODI }\end{array}$ & $\begin{array}{c}\text { Mean note duration in sec for } \\
\text { BHAIRAVI }\end{array}$ \\
\hline $\mathbf{1}$ & 0.884314 & 0.867692 \\
\hline $\mathbf{2}$ & 0.611667 & 0.306667 \\
\hline $\mathbf{3}$ & 0.516364 & 0.497143 \\
\hline $\mathbf{4}$ & 0.365625 & 0.192857 \\
\hline $\mathbf{5}$ & 0.793333 & 0.174 \\
\hline $\mathbf{6}$ & 0.628824 & 0.146667 \\
\hline $\mathbf{7}$ & 0.785 & 0.74 \\
\hline
\end{tabular}

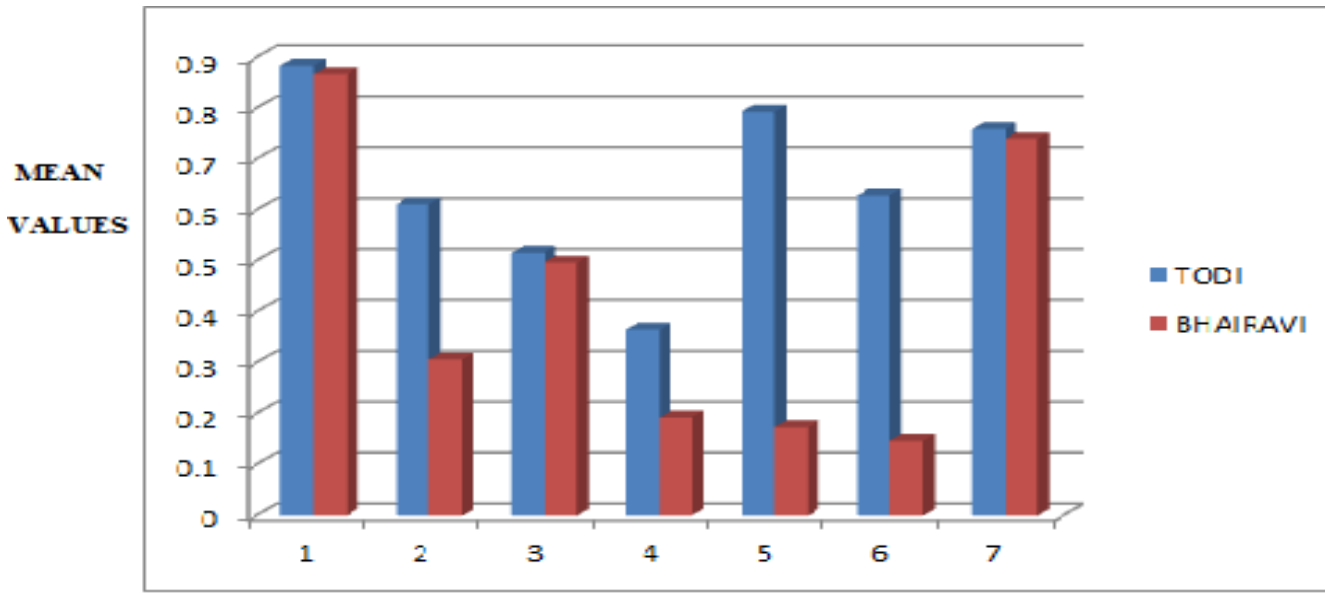

NOTES IN RAGA SAMPLE

Figure 1. Bar Diagram Showing Mean Note Duration of Todi and Bhairavi

Table 2 gives the standard deviations in sec of the note duration of the notes of Todi and Bhairavi, while Figure 2 is the bar diagrammatic display of Table 2.

Table 2. Standard Deviation of Ragas Todi and Bhairavi

\begin{tabular}{|c|c|c|}
\hline Notes & Std deviation in sec of TODI & Std deviation in sec of BHAIRAVI \\
\hline $\mathbf{1}$ & 0.9887 & 1.027226 \\
\hline $\mathbf{2}$ & 0.55241 & 0.23403 \\
\hline $\mathbf{3}$ & 0.2034 & 0.412509 \\
\hline $\mathbf{4}$ & 0.1653 & 0.421652 \\
\hline $\mathbf{5}$ & 0.6075 & 0.420214 \\
\hline $\mathbf{6}$ & 0.5223 & 0.430256 \\
\hline $\mathbf{7}$ & 0.3392 & 0.575741 \\
\hline
\end{tabular}




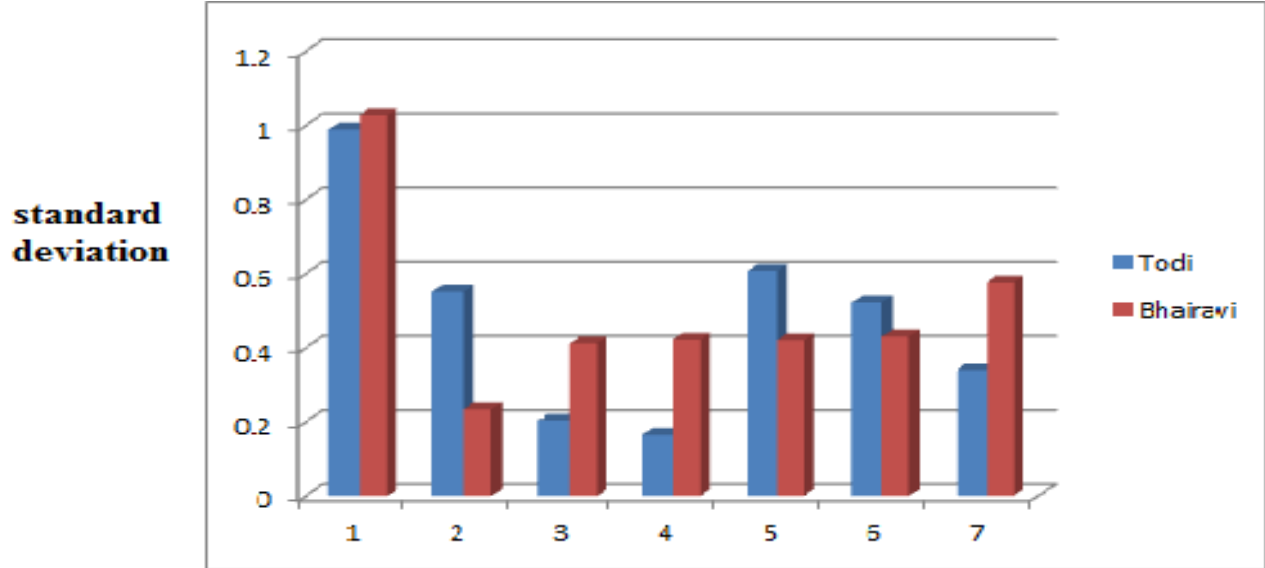

Notes of Ragas

Figure 2. Standard Deviation in sec of Ragas Todi and Bhairavi



Figure 3.1. IOI in sec of Ragas Todi

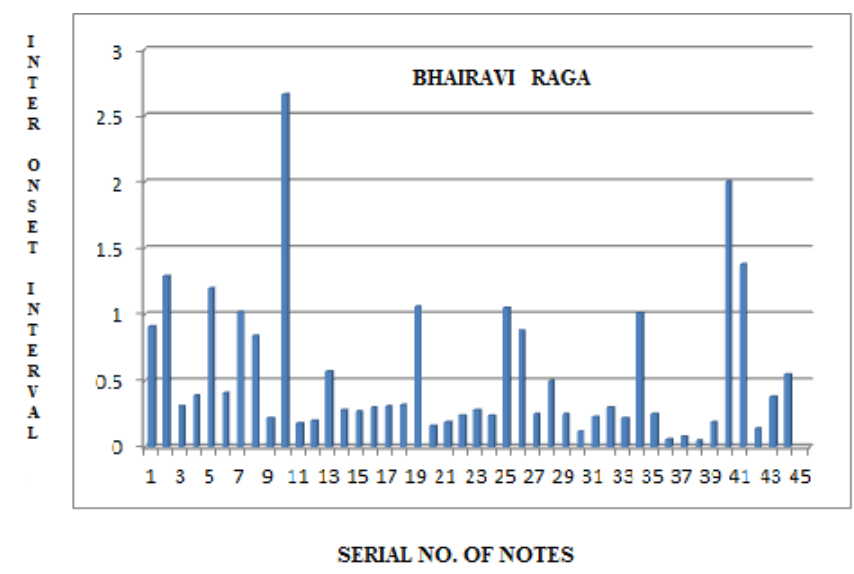

Figure 3.2. IOI in sec of Bhairavi 
Notes are in the rhythm if their inter onset interval times are equal. The concept applies to beats in a percussion instrument also such as a tabla or a drum. From the graphs of Inter onset interval (IOI) of the two ragas in sec as shown in Figures 3.1 and 3.2 it is clear that the restful raga (Todi) has a larger Inter onset interval value for many notes compared to the restless raga (Bhairavi). In other words, notes come more rapidly in Bhairavi as compared to Todi. Notes are said to be in rhythm when their IOI are equal. The notes do not seem to be in rhythm in both ragas. This is because the alaap portion was used for research purposes where the raga mood is elaborated slowly without percussion.

Figures 4.1 and 4.2 give the note duration graphs of all the notes sequentially in the two ragas. It is quite clear from these figures also that Todi is restful and Bhairavi restless.

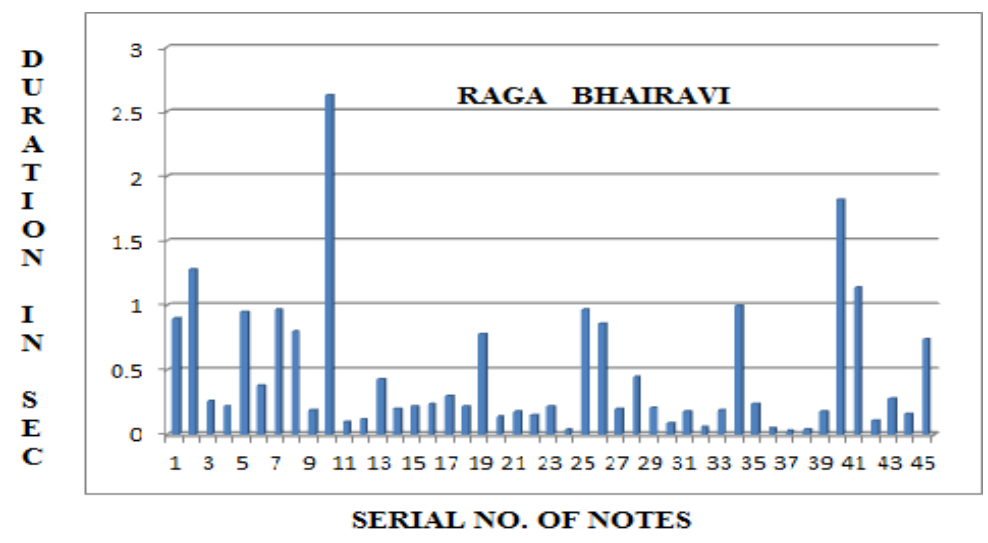

Figure 4.1. Sequential Note duration of Bhairavi

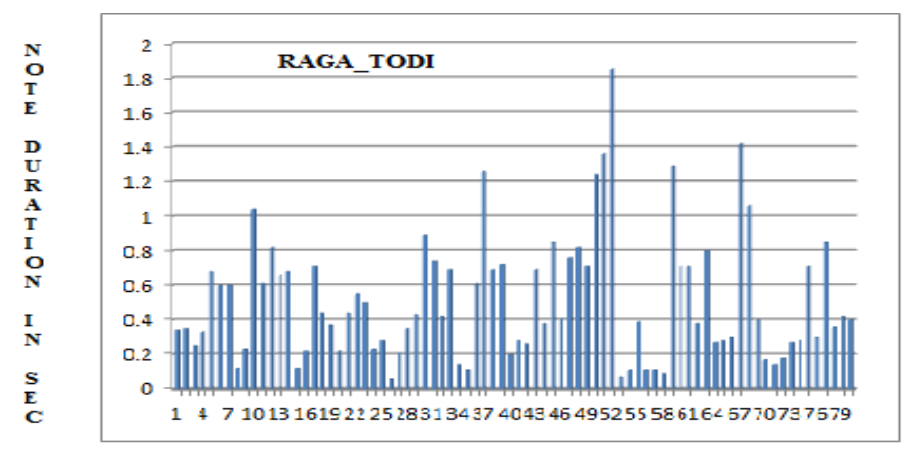

SERLAL NO. OF NOTES

Figure 4.2. Sequential Note Duration of Todi 


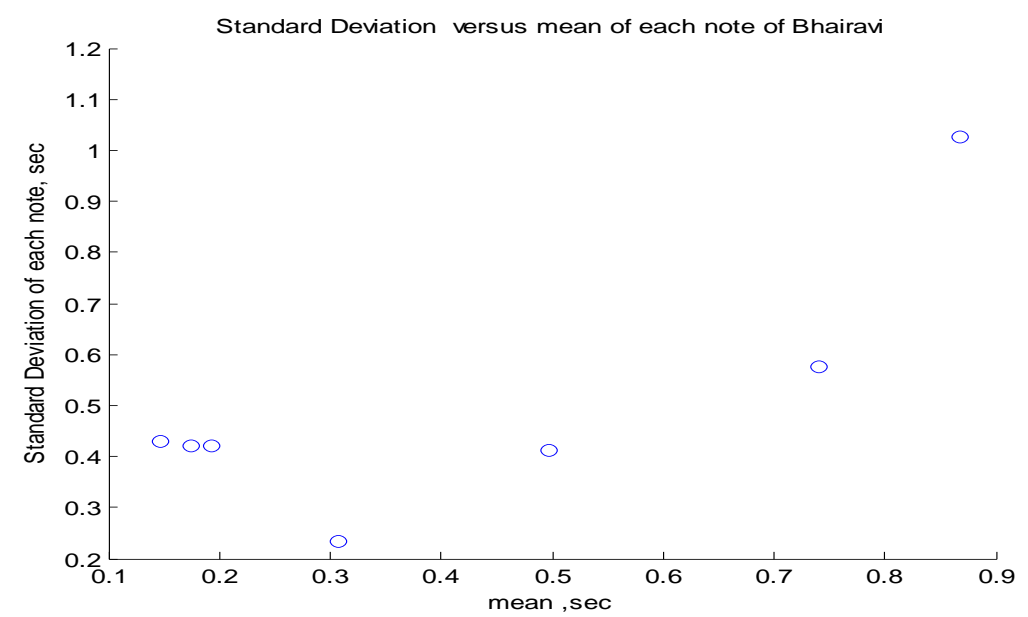

Figure 5.1. Standard Deviation versus Mean in sec of each Note of Bhairavi

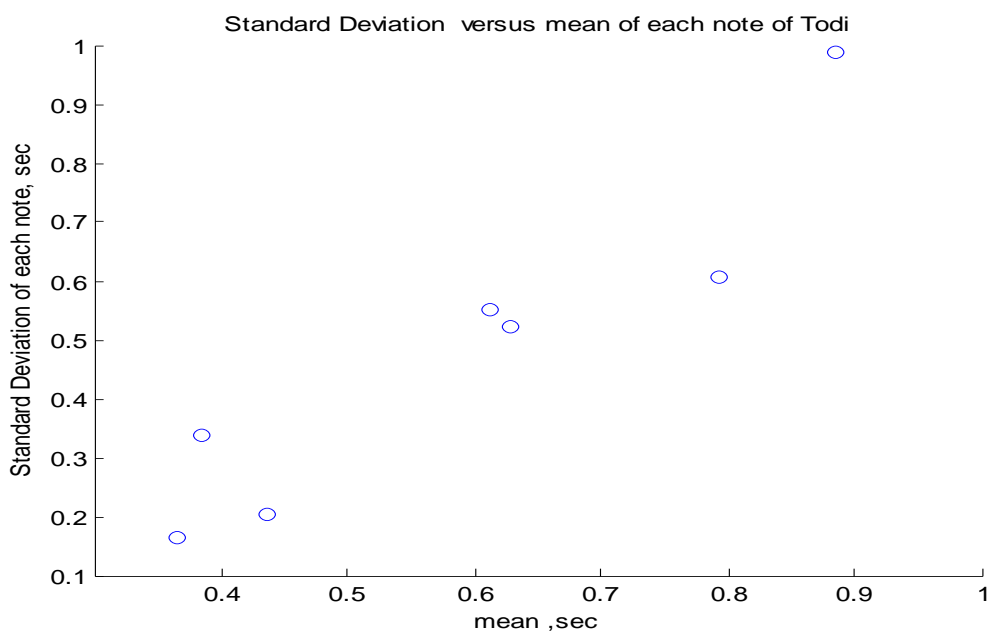

Figure 5.2. Standard Deviation versus Mean in sec of each Note of Todi

Figures 5.1 and 5.2 give the standard deviations versus the mean plots in sec of each note in the two ragas. A moments' reflection suggests that the restful raga (Todi) has the corresponding points more towards the right, indicating greater stay on the notes (higher mean duration) while at the same time the restless raga (Bhairavi) has higher corresponding points in general indicating greater variation in the note duration data, another aspect of restlessness. It is known that Bhairavi is a raga that evokes sadness and sad music is generally associated with higher note duration. Hence the experimental results have two contributions, one supportive and the other contradictory:

- Supportive: it statistically confirms the aesthetic claim that Todi is restful and Bhairavi is restless.

- Contradictory: it is an eye opener to the fact that sad music in general does not always need to be restful. 


\section{Conclusion}

Music teaching and learning are unfortunately more intuitive than logical. Therefore one way the scientific researchers can help artists is to provide a scientific basis to the aesthetic claims as made by the artists. In our case, it is musically acclaimed that Todi is a restful and serious raga and that Bhairavi is restless. However, it is important to know that Bhairavi evokes sadness although it is restless in nature. Generally it is believed that sad music is connected with higher note duration. While our statistical findings support the first claim, that is, Bhairavi is indeed a restless raga while Todi is restful, it also contradicts the other hypothesis that sad music will necessarily have higher note duration and hence be restful. It may not be so as in our case, a raga of karun rasa (sadness) such as Bhairavi is found to be restless. As a final comment, while it is difficult to provide a cut off point below which a certain musical piece is restful and above which it can be classified as restless, it is nevertheless possible, through graphical statistics, to assess which is which.

\section{Bibliography}

Beran Jan, and Mazzola, Guerino "Analyzing Musical Structure and Performance-A Statistical Approach." Statistical Science 14, no. 1 (1999): 47-79. Beran Jan Statistics in Musicology. New York: Chapman and Hall, 2004.

Chakraborty Soubhik, Mazzola Guerino, Tewari Swarima, Patra Moujhuri Computational Musicology in Hindustani Music. Springer International Publishing, 2014.

Parncutt Richard "Can researchers help artists? Music performance research for music students." Music Performance Research 1, no. 1 (2007): 1-25.

Castellano Mary A., Bharucha Jamshed J., Krumhansl Carol L. "Tonal hierarchies in the music of north India." Journal of Experimental Psychology 113, no. 3 (1984): 394-412.

Klapuri Anssi, and Davy Manuel (eds.) Signal Processing Methods for Music Transcription. New York: Springer, 2006. 